\title{
Incunabular Immunological Events in Prion Trafficking
}

SUBJECT AREAS:

IMMUNOLOGY

PROTEIN METABOLISM

NEURODEGENERATION

PROTEOLYSIS

Received

15 February 2012

Accepted

21 May 2012

Published

6 June 2012

Correspondence and requests for materials should be addressed to M.D.Z. (mark.zabel@ colostate.edu)

\author{
Brady Michel' ', Crystal Meyerett-Reid', Theodore Johnson',2, Adam Ferguson', Christy Wyckoff', \\ Bruce Pulford', Heather Bender', Anne Avery', Glenn Telling', Steven Dow' \& Mark D. Zabel'
}

${ }^{1}$ College of Veterinary Medicine and Biomedical Sciences, Department of Microbiology, Immunology and Pathology, Prion Research Program at Colorado State University, Fort Collins, Colorado, 8052 1, USA, ${ }^{2}$ National Jewish Hospital, Denver, Colorado, 80206, USA.

While prions probably interact with the innate immune system immediately following infection, little is known about this initial confrontation. Here we investigated incunabular events in lymphotropic and intranodal prion trafficking by following highly enriched, fluorescent prions from infection sites to draining lymph nodes. We detected biphasic lymphotropic transport of prions from the initial entry site upon peripheral prion inoculation. Prions arrived in draining lymph nodes cell autonomously within two hours of intraperitoneal administration. Monocytes and dendritic cells (DCs) required Complement for optimal prion delivery to lymph nodes hours later in a second wave of prion trafficking. B cells constituted the majority of prion-bearing cells in the mediastinal lymph node by six hours, indicating intranodal prion reception from resident DCs or subcapsulary sinus macrophages or directly from follicular conduits. These data reveal novel, cell autonomous prion lymphotropism, and a prominent role for B cells in intranodal prion movement.

rion diseases, also known as transmissible spongiform encephalopathies (TSEs), are fatal neurodegenerative diseases that affect humans, cervids, bovids, and ovids. According to the protein only hypothesis, the causative agent of prion diseases is a misfolded, abnormal isoform of a normal, host-encoded protein ${ }^{1}$. Termed $\mathrm{PrP}^{\mathrm{C}}$, this $30-35 \mathrm{kDa}$ glycoprotein is expressed most abundantly in the central nervous (CNS) and lymphoreticular systems, with lower expression in other tissues. The absolute requirement of $\operatorname{PrP}^{\mathrm{C}}$ expression to generate prion diseases ${ }^{2}$ and the lack of instructional nucleic acid make prions unique among infectious agents. The pathologic, protease-resistant isoform $\left(\mathrm{PrP}^{\mathrm{Sc}}\right)$ typically accumulates in the CNS and secondary lymphoid tissues of infected animals. Upon neuroinvasion, prion diseases typically progress from transformation of $\mathrm{PrP}^{\mathrm{C}}$ to $\mathrm{PrP}^{\mathrm{Sc}}$ to neuropathology including amyloid plaque formation, astrogliosis, and neuronal cell loss to inevitable death.

Before prions accumulate on follicular dendritic cells (FDCs) in secondary lymphoid organs (SLOs) ${ }^{3,4}$, they most likely interact with the innate immune system at the initial site of infection. Complement proteins like C3 and $\mathrm{Clq}$ are important innate immune molecules shown to bind foreign bodies and altered-self-particles ${ }^{5}$, including protein amyloids ${ }^{6}$ and high density prion protein ${ }^{7}$. C1q, C3 and the Complement receptor CD21/35 have been shown to expedite peripherally-induced prion pathogenesis ${ }^{8-10}$. These data suggest that initial events in prion infection include Complement opsonization and inflammatory immune cell uptake and transport of prions from initial infection sites to draining lymph nodes, where peripheral prion replication occurs. Complement may bind prions and enhance uptake by antigen presenting cells, as well as retention and replication of prions on FDCs in germinal centers.

Soluble complement proteins opsonize pathogens and facilitate their uptake by immune cells such as dendritic cells (DCs), macrophages (MФs), and monocytes surveying nonlymphoid tissues. These innate immune responses represent the first line of defense against invading pathogens. Because these immune cells act as sentinels for microbial infections, investigators have implicated them as likely candidates for the uptake and spread of prions throughout the body. Indeed, DCs, MФs, and monocytes have been reported to both positively and negatively impact prion disease pathogenesis ${ }^{8,9}$.

Although substantial evidence links immune cells to prion disease, little data directly support a role for these cells in uptake and transport of prions hours after initial exposure. Because incunabular interactions between pathogens and immune cells often dictate the outcome of infection, insight into interactions of prions with the mononuclear phagocyte system at initial infection sites and within lymph nodes is vital to understanding 
incunabular events in prion infection. In this study we analyzed the inflammatory response to prions that occurs within hours of infection, including lymphotropic and intranodal prion trafficking.

\section{Results}

Enrichment and fluorochrome conjugation of aggregated prion rods. In order to monitor prion trafficking from inoculation sites to draining lymph nodes, we first enriched prion rods from a brain of an elk terminally sick with CWD from one liter of $10 \%$ crude brain homogenate, concentrating prion aggregate volume $10^{4}$-fold to a final volume of $100 \mu \mathrm{l}$ using detergent solubilization and ultracentrifugation through a sucrose cushion (figure 1A). We enriched aggregated prion rods approximately $10^{3}$-fold (compare lanes 1 and 2 to 3 and 4). Like the crude brain homogenate, purified prion rods showed partial PK resistance (lanes 2 and 4). Normal brain homogenate contained no PK-resistant $\mathrm{PrP}^{\mathrm{C}}$ bands (lane 6). Intracranial injection of $1 \mu \mathrm{g}$ of enriched, sonicated prion aggregates resulted in terminal disease in susceptible mice $122 \pm 5(\mathrm{n}=5)$ days post inoculation (DPI) compared to $157 \pm 16 \mathrm{DPI}$ for mice inoculated with $30 \mu \mathrm{g}$ of $1 \%$ crude brain homogenate $(n=8, p=.0003)$. We then conjugated enriched prions to Dylight 649 fluorochrome (figure 1B). To evaluate the stability of the fluorochrome, we treated conjugated prions with PK (figure 1B, lanes 2 and 3) at physiological (lane 2) or supraphysiological temperatures (lane 3). DyLight 649 still fluoresced even after SDS and PK treatment followed by incubation at $95^{\circ} \mathrm{C}$. In addition to demonstrating partial SDS and PK resistance (lanes 2 and 3), fluorescent prions could also aggregate into high molecular weight oligomers (lane 1).

Prion trafficking in live animals. Resistance of fluorochrome conjugated prion rods to proteolytic and thermal degradation enabled us to visualize and track these fluorescent prions in vivo using whole mouse live imaging (Figure 1C). Inoculation of 2 and $5 \mu \mathrm{g}$ of sonicated, fluorescent prions via subcutaneous (SC) and per os (PO) routes, respectively, resulted in prion trafficking to areas consistent with the location of axillary lymph nodes within 2 hours post inoculation (HPI) PO and 4 HPI SC. Within 8 HPI SC, prions disseminate to areas consistent with the location of submandibular lymph nodes, spleen, and bladder. Prion trafficking from the oral cavity after $\mathrm{PO}$ inoculation was restricted primarily to areas consistent with the location of Peyer's patches and axillary and mesenteric lymph nodes. We observed little or no dissemination of $10 \mu \mathrm{g}$ of $1 \mu \mathrm{m}$ fluorescent polystyrene microspheres (beads) from their SC injection site, indicating specific trafficking of prion rods. a

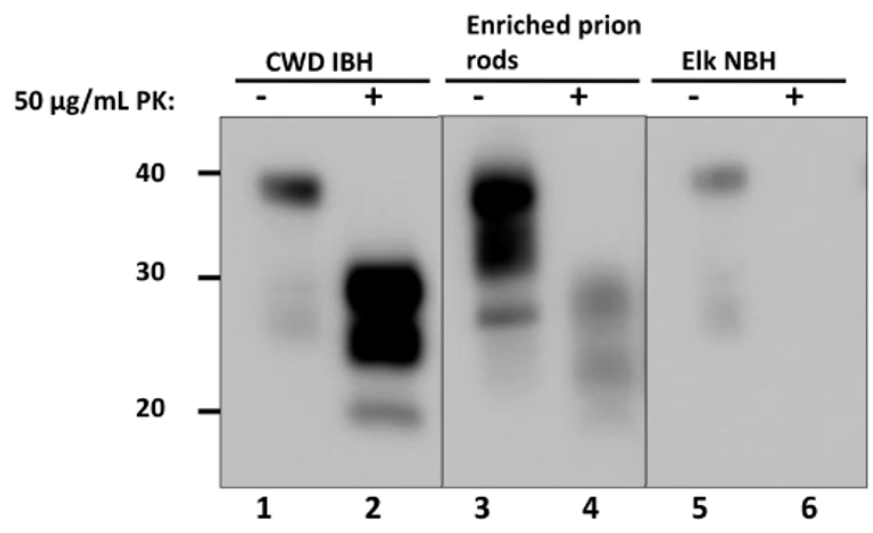

b

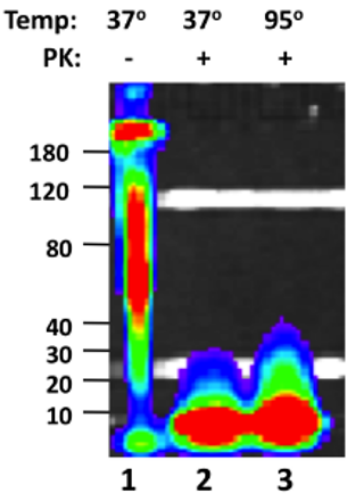
p.o.

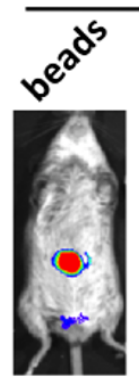

S.C.
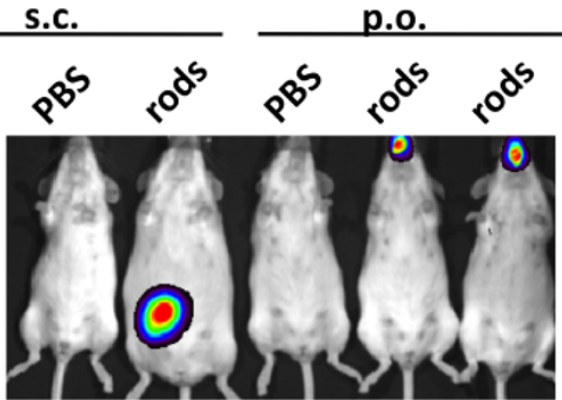

Oh
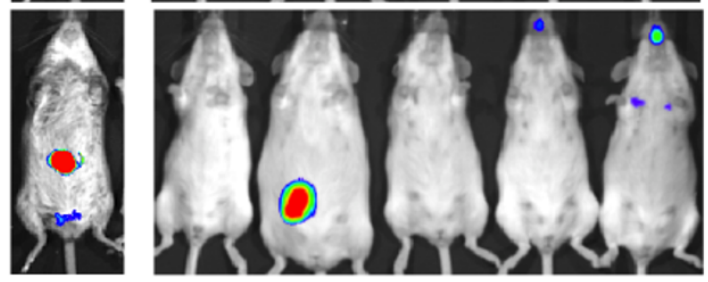

S.C.

$4 h$

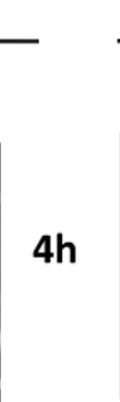

$8 \mathrm{~h}$
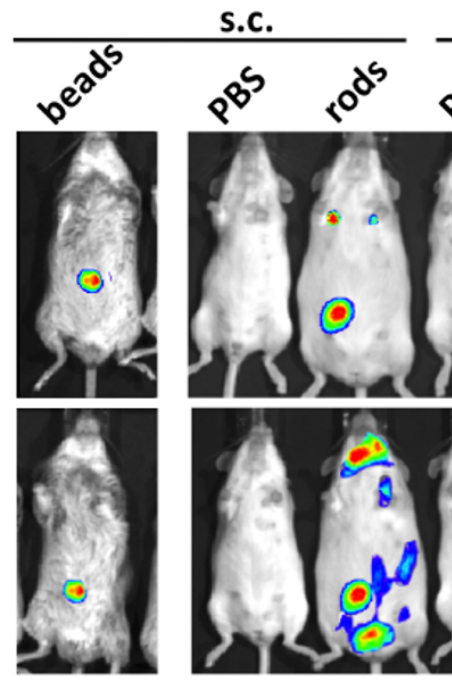

p.o.
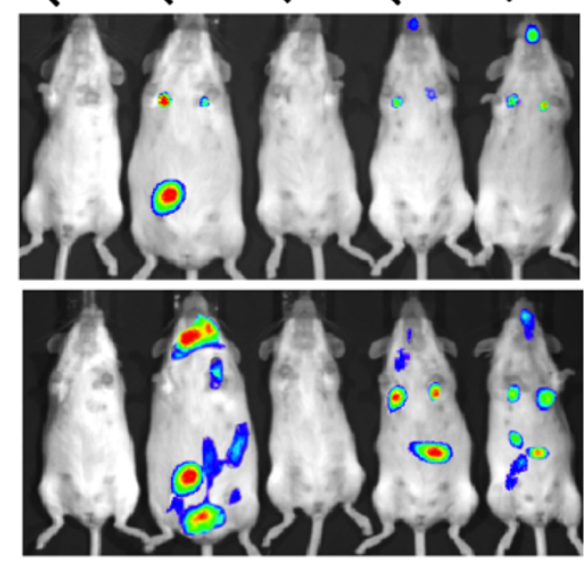

Max

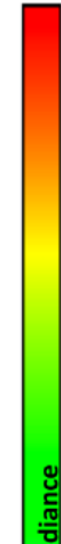

\section{$2 \mathrm{~h}$}

Figure 1 Purification and conjugation of prion rods from infected brain homogenate and real-time whole-mouse in vivo imaging. (a) Western blot analysis depicting CWD infected elk brain homogenate used as starting material (5 $\mu \mathrm{g}$ in lane 1 and $100 \mu \mathrm{g}$ in lane 2) from which we enriched prion rod aggregates (100 ng in lanes 3 and 4). Lanes 5 and 6 show $100 \mu \mathrm{g}$ of control elk normal brain homogenate. (b) SDS page gel depicting fluorochrome tagged prion rods. Prions treated at $37^{\circ} \mathrm{C}$ without Proteinase K (PK, lane 1) or with PK (lane 2), and at $95^{\circ} \mathrm{C}$ with PK (lane 3 ). Molecular weight markers are shown in kilodaltons to the left of the blots. (c) In vivo detection of prion rods by epifluorescent whole-body optical imaging. Representative images of tg5037 mice injected orally or subcutaneously with PBS or fluorescent prion rods or $1 \mu \mathrm{m}$ polystyrene microspheres (beads). Images were acquired at indicated time points after injection. 
Immune cells capture prions from the peritoneal cavity 2 HPI. Particulate antigen can be transported to SLOs via cell dependent and independent mechanisms ${ }^{10,11}$. The presence of prions, but not beads, in various locations consistent with lymph nodes that drain the injection site suggested active uptake and trafficking by migratory immune cells. To investigate this possibility, we first assessed whether immune cells associated with fluorescent prions hours after injection. Isolation of adequate cell numbers from subcutaneous tissue and the oral cavity proved difficult for characterizing innate immune cells at these injection sites. We therefore chose the peritoneal cavity (PC) as an alternative inoculation route because it provides an optimal site for collecting immune cells. We inoculated mice intraperitoneally (IP) with $5 \mu \mathrm{g}$ of fluorescent prions, collected cells by peritoneal lavage 2 HPI and analyzed them by flow cytometry (Figures 2 and 3).

DCs and MФs comprise the majority of prion-bearing immune cells (prionophils) in the PC. We observed significant acquisition of prions and $10 \mu \mathrm{g}$ of $1 \mu \mathrm{m}$ fluorescent beads by immune cells present in

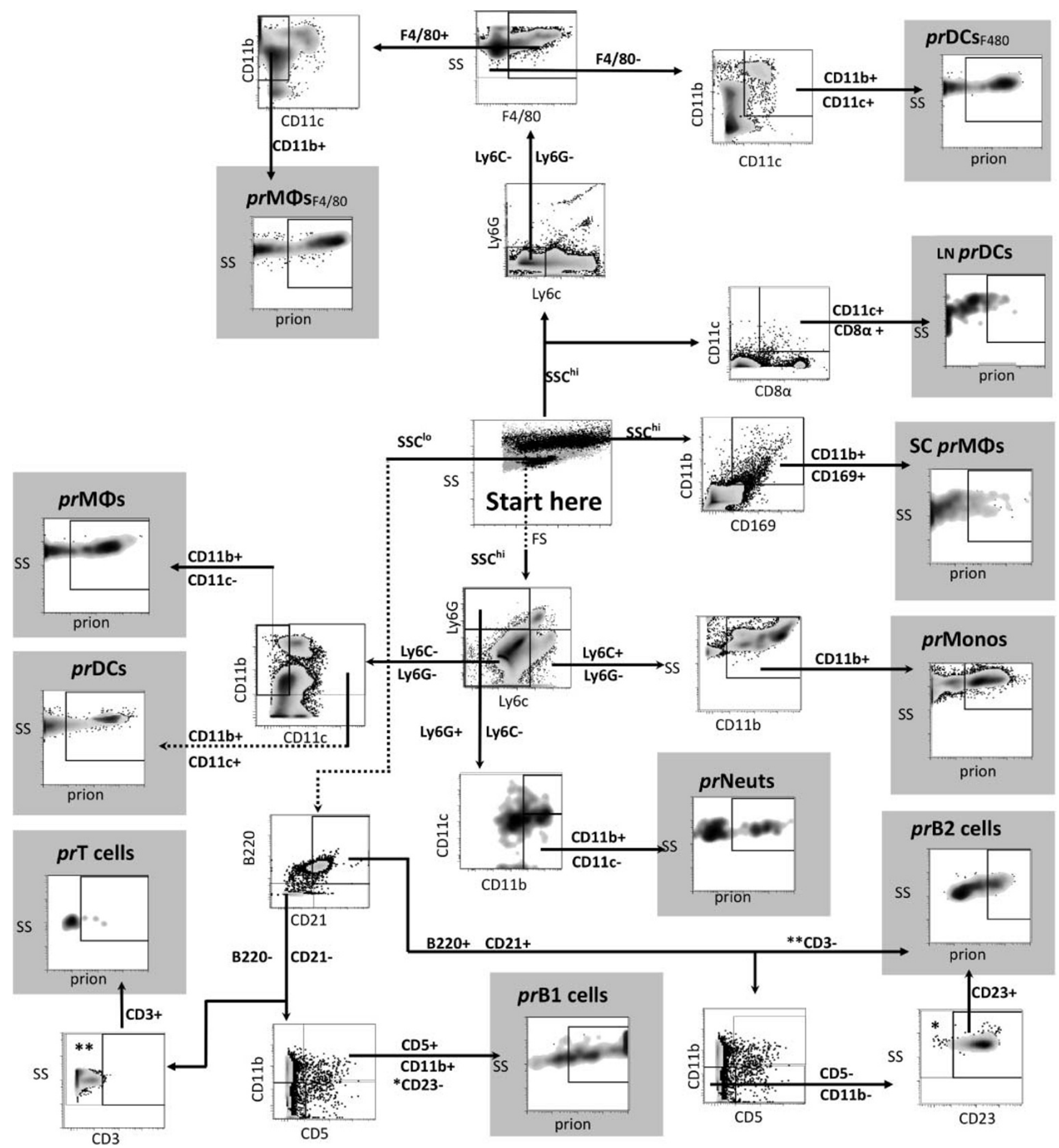

Figure $2 \mid$ Gating strategy for flow cytometry. Side scatter parameter (SS or SSC) and all other axes are log scale except forward scatter (FS). *CD23 gate

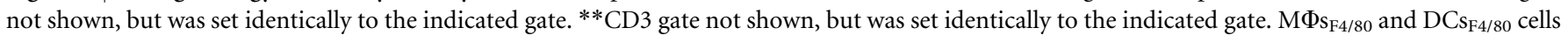
were identified using F4/80 gating. pr, prionophilic; MФs, macrophages; DCs, dendritic cells; LN, lymph node; SC, Subcapsulary. 

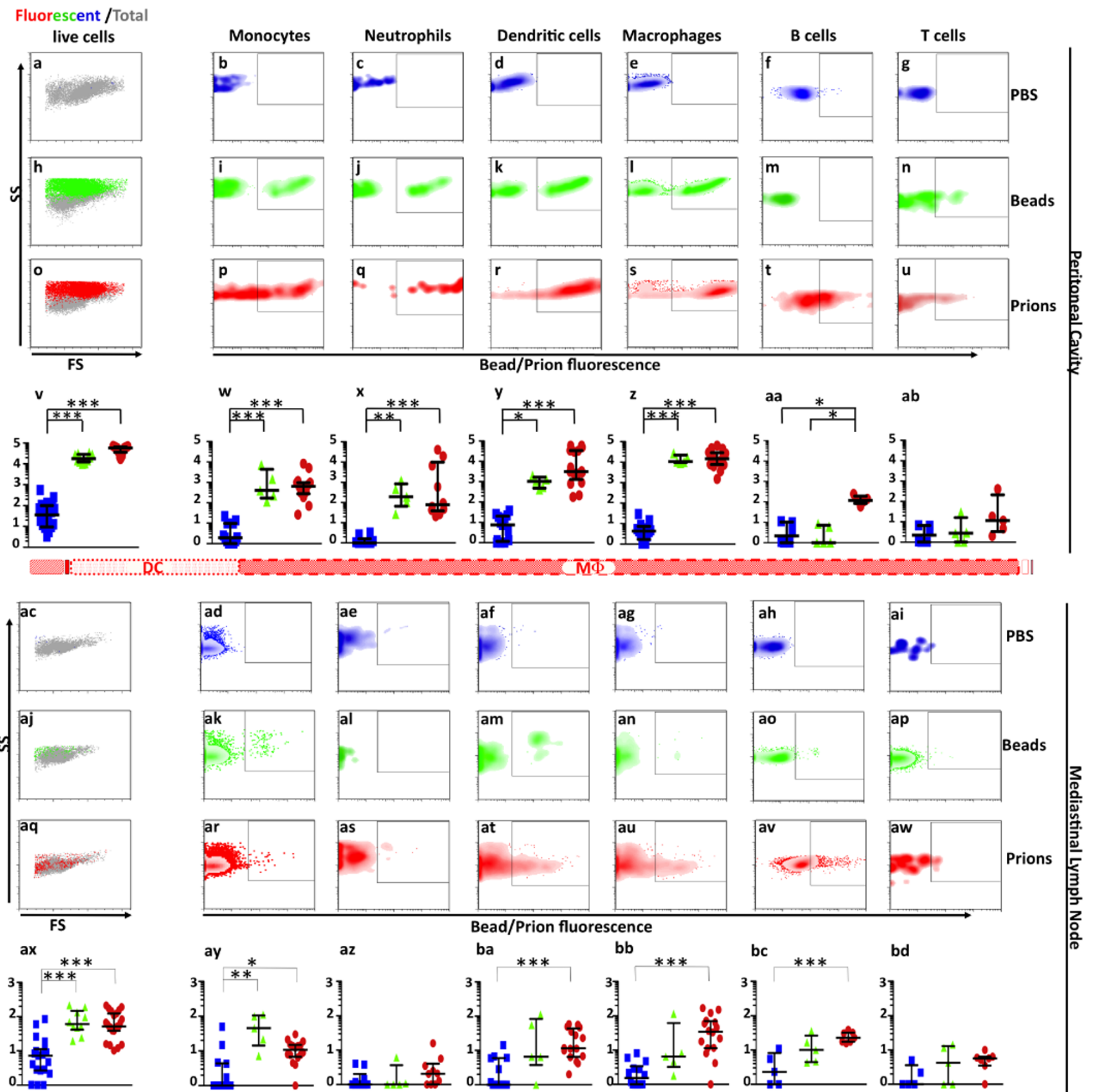

Bead/Prion fluorescence

ba

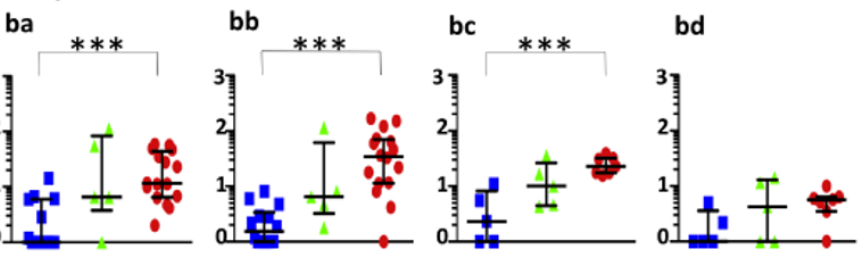

bd

mono

N:

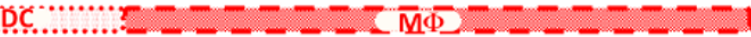

Figure 3 Flow cytometric analysis of immune cells trafficking prions from the PC to MedLN 2 HPI. PBS (rows a-g, v-ab, ac-ai, and ax-bd), fluorescent beads ( $h-n, v-a b, a j-a p$, and ax-bd) or prion rods (o-u, v-ab, aq-aw, ax-bd) were injected into the PC of mice and cells harvested from peritoneal lavage fluid ( $a-a b$ ) or mediastinal lymph nodes (ac-bd) two hours later. Graphs in the first column show cells from mice treated with PBS (panels a, v ac, and ax), fluorescent beads ( $\mathrm{h}, \mathrm{v}, \mathrm{aj}$, and ax) and prion rods (panels o, v, aq, and ax). Fluorescent cells (red or green dots) and total cells (grey dots) are plotted to show relative size (forward scatter, linear scale), granularity (side scatter, log scale) and proportion of total live cells that fluoresce. Cells were also stained with antibodies against immune cell surface markers and gated for SSChiLy6G- Ly6C+CD11b+ monocytes (panels b, i, p, w, ad, ak, ar, and ay), SSChi Ly6G+ Ly6C-CD11c- CD11b+ neutrophils (c, j, q, x, ae, al, as, and az), SSChi Ly6G- Ly6C-CD11b+CD11c+ DCs (d, k, r, y, af, am, at, ba), SSC ${ }^{\text {hi }}$ Ly6G-Ly6C-CD11c-CD11b + MФs, (e, l, s, z, ag, an, au, and b), SSC ${ }^{\mathrm{lo}} \mathrm{B} 220+\mathrm{CD} 21+\mathrm{CD} 3-\mathrm{B}$ cells (f, m, t, aa, ah, ao, av, and bc) and SSC ${ }^{\mathrm{lo}} \mathrm{CD} 21-$ B220- CD3 + T cells (g, n, u, ab, ai, ap, aw, and bd). Cell counts in graphs are shown as $\log _{10}$ per $10^{5}$ total cells. Horizontal bars below the PC and MedLN panels represent relative proportions of prion-bearing monocytes (red stripe), neutrophils (solid red), DCs (dotted), MФs (checkered), B cells (white) and T cells (black).

the PC 2 HPI compared to PBS (Figures $3 \mathrm{a}, \mathrm{h}$ and $\mathrm{o}$ ). Of the major antigen presenting cells analyzed from the $\mathrm{PC}$, $\mathrm{SSC}^{\text {hi }} \mathrm{Ly}_{6 \mathrm{G}}{ }^{-} \mathrm{Ly} 6 \mathrm{C}^{-} \mathrm{CD} 11 \mathrm{~b}^{+} \mathrm{CD} 11 \mathrm{c}^{+}$DCs (Figure 2 and $3 \mathrm{r}$ ) and

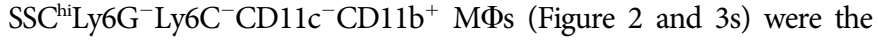
predominant cell types capturing prions. Upregulation of CD11c on inflammatory MФs can complicate their discrimination from DCs. 
Although we observed no increase in CD11c+ cells in the PC, we performed an alternative gating strategy that gated for SSChi Ly6C-

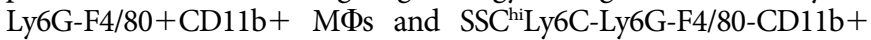
$\mathrm{CD} 11 \mathrm{c}+\mathrm{DCs}$ (Figure 2) to more clearly define these two cell populations. Both strategies yielded very similar results, and are reported here as combined data. We detected significant numbers of prionophilic DCs ( $p r D C s$, Figure 3y, median=3177; IQR $=1280$ to 33,968 per 100,000 cells, $\mathrm{n}=16$ mice) and $\mathrm{M \Phi s}$ (prMФs, Figure $3 \mathrm{z}$, median= $14,730, \mathrm{IQR}=7598$ to $29037, \mathrm{n}=16$ ) compared to DCs and MФs from mice inoculated with PBS alone ( $p b s \mathrm{DCs}$, Figures $3 \mathrm{~d}$ and $\mathrm{y}$, e and $\mathrm{z}$, median $=8, \mathrm{IQR}=1$ to 20 and $p b s \mathrm{M} \Phi s$, median $=4, \mathrm{IQR}=1$ to 7, respectively, $\mathrm{n}=13, \mathrm{p}<0.001)$. prM $\Phi$ s and prDCs accounted for $78.6 \%$ and $16.9 \%$, respectively, of total prionophils.

DCs and B cells preferentially capture prions. Comparing two particulate antigens, we detected three-fold more prDCs (median= 3177 ) than bead-bound DCs ( $b$ DCs, median $=1037, \mathrm{IQR}=479$ to $1654, n=5, p=0.0262$, Figure $3 K$ and $Y$ ). In a subset of mice whose cells acquired prions, we observed 40 -fold more prDCs (6/ 16 , median $=41,905$. $\mathrm{IQR}=31,234$ to $59,043, \mathrm{p}=0.0022)$ than $b \mathrm{DCs}$.

We observed a small proportion ( $0.6 \%$ of total), yet significant number, of prionophilic SSC ${ }^{\mathrm{lo}} \mathrm{B} 220+\mathrm{CD} 21+\mathrm{CD} 3-\mathrm{B}$ cells $(\mathrm{prB}$ cells, Figures 2 and $3 \mathrm{t}$ and aa, median $=117, \mathrm{IQR}=84$ to 192 $\mathrm{p}<0.05$ ) in the $\mathrm{PC}$ compared to $\mathrm{PBS}$ (Figures $3 \mathrm{f}$, and aa, median $=2$; $\mathrm{IQR}=0$ to 10 ) but little to no bead-bearing $\mathrm{B}$ cells (Figures $3 \mathrm{~m}$ and $\mathrm{AA}$, median $=0, \mathrm{IQR}=0$ to $7, \mathrm{n}=5$ ). We detected no significant difference in numbers of peritoneal prMФs or bead-bearing MФs (Figure 31 and $z$, median $=10,700 ; \mathrm{IQR}=9658$ to $22,144, \mathrm{n}=5$ ).

Relatively few Monocytes and Neutrophils capture prion rods from the PC. SSC ${ }^{\text {hi }} \mathrm{Ly} 6 \mathrm{G}^{-} \mathrm{Ly} 6 \mathrm{C}^{+} \mathrm{CD} 11 \mathrm{~b}+$ monocytes and $\mathrm{SSC}^{\text {hi }} \mathrm{Ly} 6 \mathrm{C}^{-} \mathrm{Ly}_{6 \mathrm{G}}{ }^{+} \mathrm{CD} 11 \mathrm{c}^{-} \mathrm{CD} 11 \mathrm{~b}^{+}$neutrophils (Figure 2) also show a propensity to retain prions from the PC $2 \mathrm{HPI}$. We collected significant numbers of prionophilic monocytes (prMonos, Figure $3 \mathrm{p}$ and $\mathrm{w}$, median $=638, \mathrm{IQR}=276$ to $967, \mathrm{n}=16$ ) and neutrophils ( $p r$ Neuts, Figure $3 \mathrm{q}$ and $\mathrm{x}$, median $=77, \mathrm{IQR}=38$ to $9874, \mathrm{n}=10$ ) compared to PBS inoculated controls ( $p b s$ Monos, Figures $3 \mathrm{~b}$ and $\mathrm{w}, \mathrm{c}$ and $\mathrm{x}$, median $=2$; IQR 0 to $10, \mathrm{n}=13$ and $p b s$ Neuts, median $=0, I Q R 0$ to $2, \mathrm{n}=10 ; \mathrm{p}<0.001)$. Additionally, neutrophils exhibited the highest propensity for prion rod uptake, with up to $98 \%$ of neutrophils in PC capturing prions. Still, prMonos and prNeuts comprised only $3.4 \%$ and $0.4 \%$, respectively, of total prionophils. We also collected significant numbers of beadassociated monocytes $(b$ Monos, Figure $3 \mathrm{i}$ and $\mathrm{w}, \mathrm{j}$ and $\mathrm{x}$, median $=$ $401, \mathrm{IQR}=171$ to $4388 ; \mathrm{p}<0.01)$ and neutrophils ( $b$ Neuts, IQR $=66$ to $839 ; \mathrm{n}=5, \mathrm{p}<0.01$ ) compared to $\mathrm{PBS}$, but observed no difference in numbers of prMonos/Neuts versus $b$ Monos/Neuts. Finally, We detected no significant numbers of prionophilic or bead-associated $\mathrm{SSC}^{\mathrm{lo}} \mathrm{B} 220-\mathrm{CD} 21-\mathrm{CD} 3+\mathrm{T}$ cells (Figure 2, prT and $b \mathrm{~T}$ cells, respectively) in the PC at 2 HPI (Figures $3 g, n, u$ and $a b$ ). We observed similar prionophil quantities and proportions from identical experiments using $\operatorname{PrP}^{\mathrm{C}}$ deficient mice (data not shown).

Prionophils are present in the MedLN 2 HPI. We then searched for prionophils in LNs to which these cells migrate. We failed to identify significant numbers of prionophils in spleens or mesenteric lymph nodes in this assay, as expected for antigens injected IP. However, we observed significant acquisition of fluorescent prions and beads by immune cells present in the mediastinal lymph nodes (MedLN) 2 HPI compared to PBS (Figures 3AC, AJ and AQ). We also observed trafficking to inguinal lymph nodes, but at lower frequencies and cell counts compared to MedLNs (data not shown). Confocal microscopy revealed large prion aggregates in areas of MedLNs consistent with lymphoid follicles and capsules (Figure S1). Interestingly, we observed drastic changes in prionophil proportions in the MedLN compared to the PC.
MФs and B cells comprise the majority prionophils in the MedLN. We observed more prMФs than any other immune cell type analyzed (Figure $3 \mathrm{au}$ and $\mathrm{bb}$, median $=34, \mathrm{IQR}=11$ to $70 \mathrm{n}=16$, compared to pbsM $\Phi$ s (Figures ag and bb, median $=0, \mathrm{IQR}=0$ to 6 and $\mathrm{n}=13$, $\mathrm{p}<0.001)$ ), consistent with their predominance in the PC. Surprisingly, though, prB cells represented the second highest number of prionophils in the MedLN (Figures av and bc, median $=23, \mathrm{IQR}=17$ to $32 \mathrm{p}<0.01$ compared to PBS inoculated controls). This represents a 44-fold increase in the proportion of prB cells in the MedLN (26.4\%) compared to the PC (0.6\%). The proportion of prMФs decreased 2.1-fold from the MedLN (39.1\%) compared to the PC (78.6\%). We detected statistically insignificant numbers of $b \mathrm{M} \Phi$ s (Figure 3 an and $\mathrm{BB}$, median $=6 ; \mathrm{IQR}=3$ to 61 , $\mathrm{n}=5$ ) and $b B$ cells (Figure 3 ao and $\mathrm{BC}$, median $=10, \mathrm{IQR}=4$ to 26 ) in the MedLN.

Increased proportion of monocytes in the MedLN. We collected half as many prMonos (Figure 3 ar and ay median $=11$; IQR 7 to 15 ; $\mathrm{p}<0.05$ ) and $p r D C s$ (Figure 3at and ba, median $=11 ; \mathrm{IQR}=6$ to 44 per $10^{5}$ cells, $\mathrm{n}=16$ mice) from the MedLN compared to prB cells. The proportion of prMonos increased 3.7-fold in the MedLN (12.6\%) compared to the PC (3.4\%), while prDC proportions decreased slightly. Interestingly, we detected four-fold more $b$ Monos (Figure $3 \mathrm{ak}$ and ay median $=45 ; \mathrm{IQR}=14$ to $105 ; \mathrm{p}<0.01$ ) than prMonos. We observed no significant difference in the number of $p r \mathrm{DCs}$ and $b \mathrm{DCs}$ (Figure $3 \mathrm{am}$ and ba, median $=7, \mathrm{IQR}=3$ to 83 , $\mathrm{n}=5$ ), and found no significant numbers of prNeuts (Figure 3 as and $\mathrm{az}$ ), $b \mathrm{Neuts}$ (al and az), prT (aw and bd) or $b \mathrm{~T}$ (ap and bd) cells in the MedLN.

Peritoneal prionophils both internalize and retain prion rods on their cell surfaces. We assessed subcellular location of captured prions by visulaizing peritoneal prionophils by confocal microscopy. While prMonos (Figure 4) and prMФs (Figure S2) showed a tendency to internalize prion rods, these cells, as well as prDCs (Figure S3), and prNeuts (Figure S4) demonstrated the ability to retain prion rods on both the cell surface and intracellular compartments. Internalized fluorescent prions generally appeared more diffuse, while cell surface prions appeared as bright, punctate fluorescent aggregates ranging in size from $1-3 \mu \mathrm{m}^{3}$ on cell surfaces.

Dynamics of prion trafficking kinetics over time. Most prionophil proportions in the PC remained relatively constant from 2 to 36 hours (Figure S5), except for a 26-fold increase in prNeuts from $2(0.4 \%)$ to 6 HPI $(10.3 \%)$. Consistent with data collected 2 HPI, at 6 HPI prB cells increased their proportion 201-fold from the PC (Figure S6, 0.3\%) to the MedLN (60.3\%), becoming the predominant prionophil, while the prM $\Phi$ proportion decrease 6.4fold from the PC (70.9\%) to the MedLN (11.1\%). By 16 HPI, we observed a relatively even distribution of all prionophils analyzed, save prNeuts (Figures S5 and S7). The share of prDCs increased 4.4fold from the PC to MedLN at $16 \mathrm{HPI}$, then plateaued to $36 \mathrm{HPI}$ (Figures S5 and S8). Proportions of prMonos from PC to MedLN increased steadily over every time point, reaching its maximum share of total prionophils in the MedLN at 36 HPI (41.8\%). The distribution of the other prionophils analyzed remained relatively constant from 16 to $36 \mathrm{HPI}$, except for prMonos, whose percentage increased two-fold over that time. We failed to detect any fluorescent prions or beads one week after inoculation (data not shown).

Passive and active transport of prions to MedLNs. Previous studies indicate that DC trafficking antigen to draining lymph nodes occurs 12-16 $\mathrm{HPI}^{10-12}$. Given the early detection of prionophils in the MedLN in as little as $2 \mathrm{HPI}$, we postulated passive prion delivery might occur at early time points whereas active transport by prionophils may occur later in infection. To test this hypothesis we 




Figure $4 \mid$ Analysis of monocytes capturing prion rods in the PC by confocal microscopy. PBS and prion rods (labeled red) were injected into the PC of mice and CD11b + Ly6C + (labeled blue and green, respectively) monocytes were analyzed for prion retention. $\mathrm{Z}$ stack images were collected at $0.28 \mu \mathrm{m}$ intervals and range from 0.64 to $7.31 \mu \mathrm{m}$. Image shown in row three, column six indicates isotype and PBS controls. Bottom row starting from the left show single stains of the nucleus (white), Ly6C, CD11b, and prion rods. The Last 2 panels in the bottom row represent a merged $\mathrm{z}$ stack image and an orthogonal image.

injected prions IP into the PC of donor mice and harvested cells from the PC and MedLN two hours later. Peritoneal cells from donor mice were washed to remove unbound prions and $10^{6}$ cells transferred into the PC of each recipient mouse. MedLN from donor and recipient mice were analyzed for resident and migratory prionophils, respectively.

SSC ${ }^{\text {hi }} \mathrm{CD} 11 \mathrm{~b}+\mathrm{CD} 169+$ subcapsulary sinus MФs (SCS MФs, Figure 5a) isolated from donor mice show a high propensity for prion uptake 2 HPI (Figure 5b (red cloud) and $5 \mathrm{~d}$ (red dots), median $=94$; $\mathrm{IQR}=27$ to 148 per 100,000 cells, $\mathrm{n}=17$ mice, $\mathrm{p}<0.01$ ) compared to mice inoculated with PBS (Figure 5b (blue cloud) and $5 \mathrm{~d}$ (blue squares, median $=6$; IQR 2 to $7, \mathrm{n}=3$ mice). $S S C{ }^{\text {hi }} \mathrm{CD} 11 \mathrm{c}+\mathrm{CD} 8 \alpha+$ resident DCs also show a significant ability to take up prions (Figure $5 \mathrm{c}$ and $5 \mathrm{e}$ (red cloud and dots) median $=8$; IQR 4 to 11 , $\mathrm{n}=17, \mathrm{p}<0.05)$ compared to PBS controls (blue cloud and dots, median $=2$; IQR 1 to $5, \mathrm{n}=3$ ).

We assessed active prion transport by isolating cells from the MedLN of recipient mice inoculated with prion-loaded donor cells. We detected a small number of prMonos in MedLNs at two HPI (Figure $5 \mathrm{f}, \mathrm{h}$, and $\mathrm{j}$, median $=6 \mathrm{IQR}=4$ to 24 ) and $16 \mathrm{HPI}$ (Figure $5 \mathrm{~g}$, i, and $\mathrm{k}$, median $=4 \mathrm{IQR}=1$ to 9 ). While these median numbers are low, we did detect 13 and 181 prMonos in two mice, and 15 prMФs in one mouse at $16 \mathrm{HPI}$.

We also performed adoptive transfer experiments at $6 \mathrm{HPI}$ to analyze MedLN cells for prB cells to assess the drastic increase in their proportions at this time point. In donor MedLNs we detected significant numbers of prionophilic SSC ${ }^{\text {lo }} \mathrm{CD} 5-\mathrm{CD} 11 \mathrm{~b}-$ $\mathrm{B} 220+\mathrm{CD} 23+\mathrm{CD} 21+$ follicular B2 cells (prB2, Figure $6 \mathrm{~b}$ and D, median $=24 ; \mathrm{IQR}=3$ to $40, \mathrm{n}=5, \mathrm{p}=0.008$ ). Surprisingly, we also detected significant numbers of prionophilic SSClo B220-CD21$\mathrm{CD} 23-\mathrm{CD} 11 \mathrm{~b}+\mathrm{CD} 5+\mathrm{B} 1$ cells $(p r \mathrm{~B} 1$, Figure $6 \mathrm{c}$ and e, median $=7$; IQR 4 to $21, \mathrm{n}=7, \mathrm{p}=0.005)$ there. MedLNs from recipient mice contained prB2 (Figure $6 \mathrm{~g}$ and $\mathrm{h}$, red peak and dots, median $=108$ per $10^{4} \mathrm{~B}$ cells, $\mathrm{IQR}=41$ to $179, \mathrm{p}=0.045$ ), but not $p r \mathrm{~B} 1$ (green, median $=1, \mathrm{IQR}=1$ to 29 ) cells $6 \mathrm{HPI}$.

The role of Complement in prionophil uptake and trafficking of prions 2 HPI. Complement facilitates prion pathogenesis, replication and uptake by FDCs and conventional $\mathrm{DCs}^{13-15}$. To examine the interplay of complement with prions in early inflammatory events involving the MPS, we inoculated mice deficient in complement components $\mathrm{C} 1 \mathrm{q}$ or $\mathrm{C} 3$ with prions IP and analyzed immune cells from the PC and MedLN for prion retention 2 HPI.

Impaired ability of DCs from Complement deficient mice to capture prions from the PC. While $\mathrm{Clq}^{-1-}$ and $\mathrm{C3}^{-1-}$ mice possessed similar numbers of total prionophils in the $\mathrm{PC}$, they exhibited altered prionophil proportions compared to controls (Figure 7, panels $\mathrm{f}, \mathrm{k}, \mathrm{p}$, and $\mathrm{u}$ ). We detected fewer prDCs from $C 1 q^{-1-}$ (panels $6 \mathrm{n}$ and $\mathrm{x}$, median $=390 ; \mathrm{IQR}=184$ to $1077 \mathrm{n}=11$, $\mathrm{p}=0.01$ ) or $C 3^{-1-}$ mice (6s and $\mathrm{x}$, median $=913 ; \mathrm{IQR}=165$ to 1492 $\mathrm{n}=7, \mathrm{p}=0.01$ ) than from wt mice ( $\mathrm{i}$ and $\mathrm{x}$, median $=3089$; $\mathrm{IQR}=982$ to $33614 \mathrm{n}=17, \mathrm{p}=0.001)$. Concomitantly, we observed increases in prNeuts from $\mathrm{Clq}^{-1-}(6 \mathrm{~m}$ and $\mathrm{w}$, median 4006; $\mathrm{IQR}=296$ to $8508 \mathrm{n}=11, \mathrm{p}=0.01)$ and $C 3^{-1-}(6 \mathrm{r}$ and $\mathrm{w}$, median 


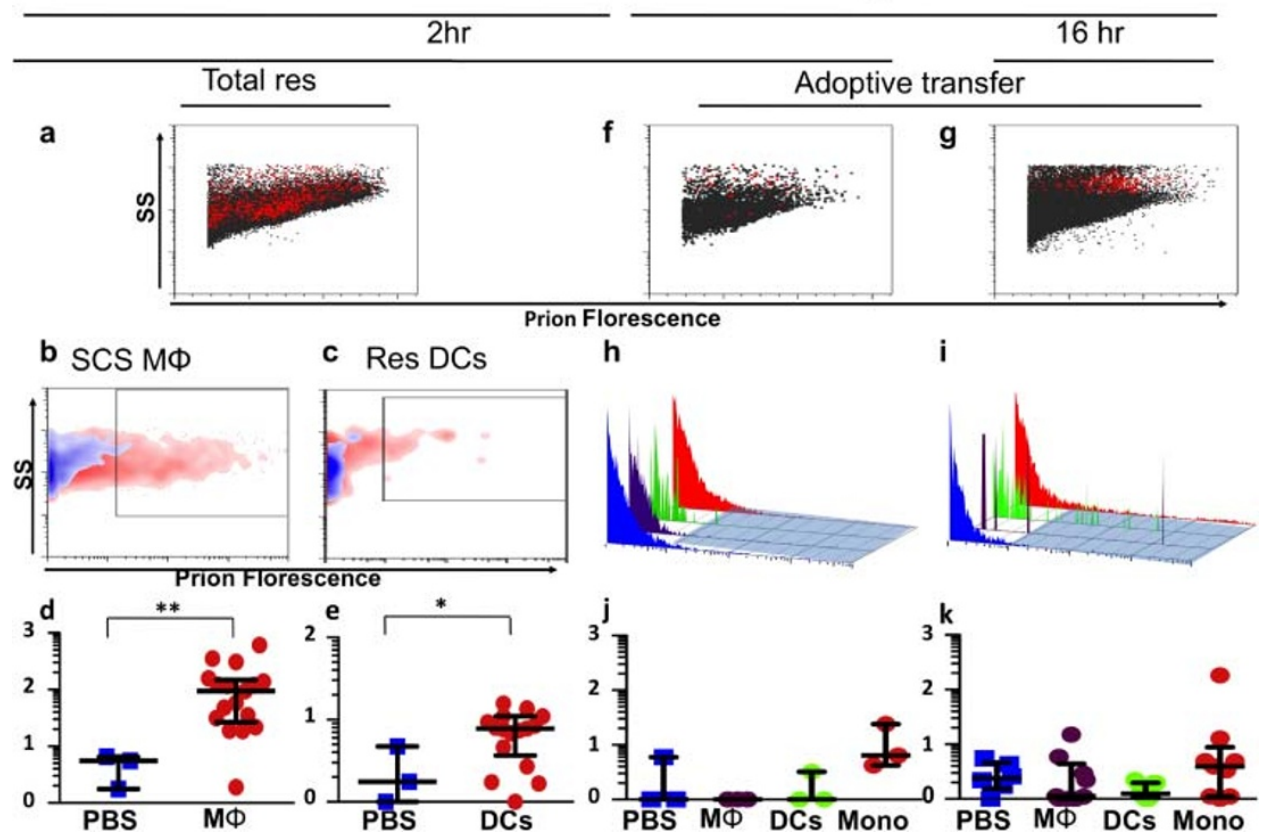

Figure $5 \mid$ Flow cytometric analysis of passive and active transport of prion rods. Prion rods were injected IP into donor mice and two hours later immune cells harvested from the PC and mediastinal lymph nodes. Peritoneal cells were washed to remove unbould prion rods and transferred into the PC of recipient mice. MedLN from donor mice 2 HPI (panels a-e), and recipient mice 2 and 16 HPI (panels f-k), were analyzed for prion-bearing resident and migratory immune cells, respectively. Total cells from the MedLN (grey dots in panels a, f and g) are plotted to show relative size (forward scatter, linear scale), granularity (side scatter, $\log$ scale) and proportion of total live cells that bear prions (red dots). Resident MedLN cells were analyzed for

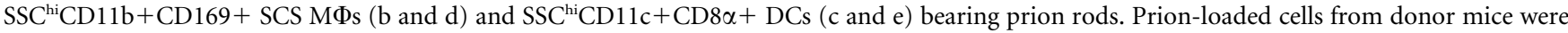
injected into the PC of recipient mice and lymph nodes harvested 2 and 16 hours later. Migratory immune cells were also analyzed for monocytes (depicted as red peaks (h and i) and dots (Jjand k)), DCs (green) and MФs (purple) using the same phenotypic markers used in Figure 3. These cell subsets were compared to cells in MedLN from PBS inoculated control mice (blue). Cell counts in graphs $\mathrm{d}, \mathrm{e}, \mathrm{j}$ and $\mathrm{k}$ are shown as $\log _{10}$ per $10^{5}$ total cells.
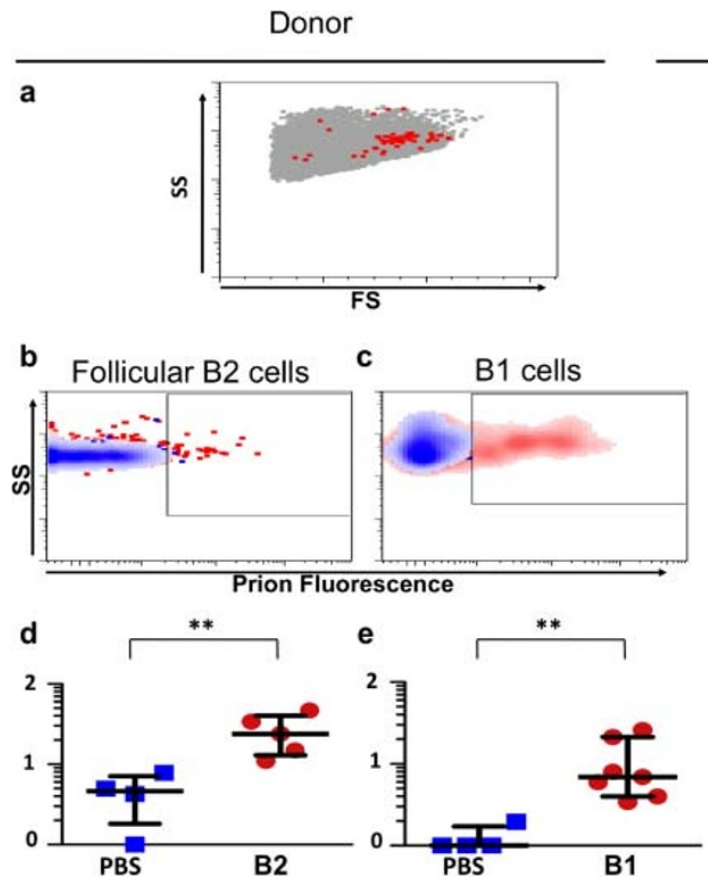

Figure 6 | Flow cytometric analysis of B cell subsets in transport of prion rods. Adoptive transfer experiment was performed similarly as experiments in Figure 5. Prion rods were injected IP into donor mice and six hours later immune cells harvested from the PC were washed and transferred into the PC of recipient mice. MedLN from donor (panels a-e) and recipient mice (panels $\mathrm{f}-\mathrm{h}$ ) were analyzed 6 HPI for prion-bearing B1 and B2 cells. Donor MedLN cells were analyzed for SSC ${ }^{\mathrm{lo}} \mathrm{CD} 21^{+} \mathrm{B} 220^{+} \mathrm{CD} 5^{-} \mathrm{CD} 11 \mathrm{~b}-\mathrm{CD} 23^{+}$follicular B2 cells (b and d) and SSC ${ }^{\text {lo }} \mathrm{B} 220^{-} \mathrm{CD} 21^{-} \mathrm{CD} 23^{-} \mathrm{CD} 11 \mathrm{~b}^{+} \mathrm{CD} 5^{+} \mathrm{B}-1 \mathrm{cells}(\mathrm{c}$ and e) bearing prion rods. Recipient MedLNs were also analyzed for prion uptake by B2 cells (red peak (g) and dots (h)) and B1 cells (green). B cell subsets were compared to cells in MedLN from PBS inoculated control mice (blue). Cell counts in graphs are shown as $\log _{10}$ per $10^{5}$ total cells $\left(\mathrm{d}\right.$ and e) or per $10^{4}$ B cells (h). 


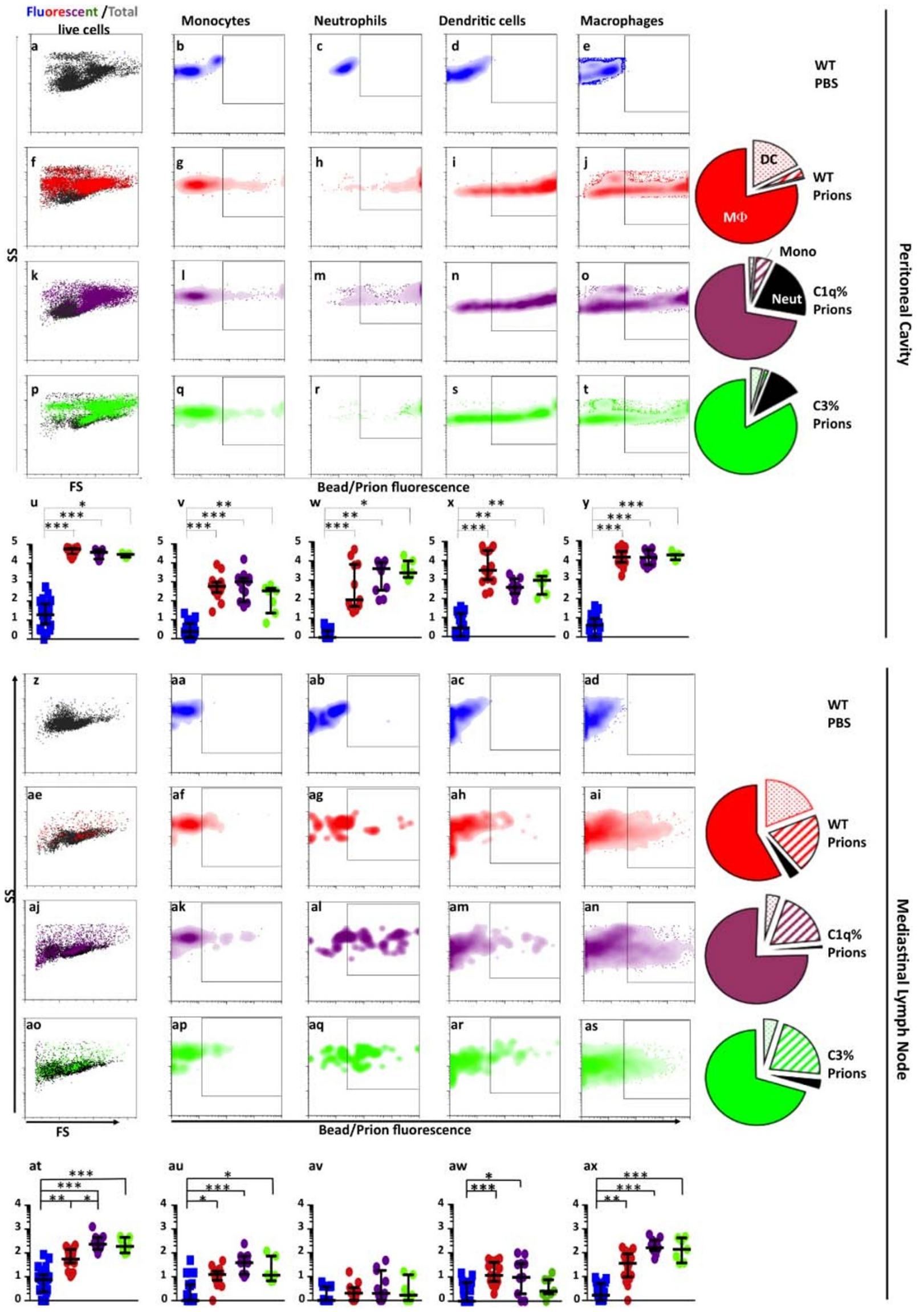


Figure $7 \mid$ Flow cytometric analysis of immune cells trafficking prions in complement deficient mice. Figure panels are arranged similarly as in Figure 4. Pie charts to the right of the flow cytographs of prionophils from wt $(\mathrm{f}-\mathrm{j}), C 1 q^{-1-}(\mathrm{k}-\mathrm{o})$ and $\mathrm{C}^{-1-}(\mathrm{p}-\mathrm{t})$ mice represent relative frequencies of prionophils.

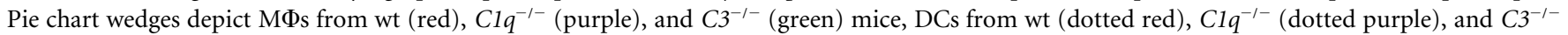
(dotted green) mice, monocytes from wt (striped red), $\mathrm{Cl}^{-1-}$ (striped purple), and $\mathrm{C}^{-1-}$ (striped green) mice, and neutrophils (black) from wt, $\mathrm{Cl} \mathrm{q}^{-1-}$, and $\mathrm{C}^{-1-}$ mice.

2420; IQR $=1383$ to $10098 \mathrm{n}=7, \mathrm{p}=0.05)$ mice compared to wt mice ( $6 \mathrm{~h}$ and $\mathrm{w}$, median 93; IQR $=42$ to $6669 \mathrm{n}=11, \mathrm{p}=0.001$ ). Consequently, the proportion of prDCs in the PC decreased 8.4-fold in $\mathrm{Cl}^{-1-}$ (Figure 7, pie chart right of panel O, dotted purple wedge) and two-fold in $\mathrm{C3}^{-1-}$ mice (dotted green wedge from panel $\mathrm{T}$ pie chart) compared to wt (dotted red wedge from Panel J pie chart), while prNeut proportions increased 40.6 and 21 -fold for $C 1 q^{-1-}$ and $C 3^{-1-}$ mice, respectively (compare black wedges in the three pie charts right of $j$, o and $t$ ). We also detected a two-fold decrease in prMonos from $\mathrm{C3}^{-1-}$ (striped green) but not $\mathrm{Cl}^{-1-}$ (striped purple) mice compared to wt (striped red). We detected no significant proportional changes in prMФs (solid colored wedges), which remained the predominant prion scavenger in the $\mathrm{PC}$ of wt ( $\mathrm{j}$ and $\mathrm{y}), \mathrm{Cl}^{-1-}$ (o and y) and $\mathrm{C3}^{-1-}$ (t and y) mice.

Impaired ability of DCs from Complement deficient mice to capture prions in the MedLN. Surprisingly, we detected more prionophils in MedLNs from both $\mathrm{C} q^{-1-}$ (Figure 7 panels aj and at) and $\mathrm{C3}^{-1-}$ (ao and at) mice compared to wt mice (panels ae and at). However, consistent with data derived from the PC, we observed an approximately four-fold reduction in the proportion of prDCs in both $\mathrm{Cl}^{-1-}$ (dotted purple wedge from pie chart right of an) and $\mathrm{C3}^{-1-}$ (dotted green wedge in chart right of as) MedLNs compared to wt (dotted red wedge, chart right of ai).

Also consistent with PC data, prMФs from wt (ai and ax, median $=36$; IQR $=11$ to $90 \mathrm{n}=17, \mathrm{p}=0.01), C 1 q^{-1-}$ (an and ax, me$\operatorname{dian}=161 ; \mathrm{IQR}=123$ to $333 \mathrm{n}=11, \mathrm{p}=0.001)$ and $C 3^{-1-}$ mice (as and ax, median $=137$; IQR $=37$ to $419 \mathrm{n}=7, \mathrm{p}=0.001$ ) constitute the majority of immune cells involved in prion uptake. We observed increases in both raw numbers (ax) and proportions of prMФs from $\mathrm{Cl}^{-1-}$ and $\mathrm{C3}^{-1-}$ mice compared to wt (compare solid colored wedges from the pie charts to the right of panels ai, an and as). Relative proportions of prMonos (striped purple, green and red wedges), prNeuts (black wedges) and prB cells (data not shown) remained similar in $\mathrm{Clq}^{-1-}, \mathrm{C3}^{-1-}$ and wt MedLNs.

\section{Discussion}

In order to gain insight into incunabular immunological events in prion infection, when the innate immune system initially confronts prions, we used highly enriched, fluorochrome conjugated prions to document prion trafficking and immune cell confrontation hours after initial exposure. We attempted to model prion trafficking as closely to a natural infection as possible using nonsaturating amounts of highly enriched, heterogeneously-sized, bona fide infectious prions. Fluorochrome conjugation of enriched prions eliminated detection using anti-prion protein antibodies, which crossreact with endogenous $\operatorname{PrP}^{\mathrm{C}}$ and complicate data interpretation.

Many studies suggest a role for MФs and CD $11 \mathrm{c}^{+}$DCs in the capture, degradation and/or transport of prions $s^{8,9,16-23}$. Consistent with these previous data, $\operatorname{prM\Phi s}$ and prDCs comprised the vast majority of prionophils detected in the PC 2 HPI, while prMonos, prB cells and $p r N e u t s$ comprised the remaining small fraction. Only DCs and B cells preferentially captured prions over beads, evincing receptor mediated capture by these cells, perhaps by innate immune receptors as previously suggested ${ }^{7,13,15,24}$.

Based on current paradigms of cell-mediated trafficking of antigens ${ }^{10,25-27}$, including prions ${ }^{22,24}$, from infection sites to draining lymph nodes, we expected to find few prionophils in the MedLN before 16 HPI. Instead, we found considerable numbers of prMФs, prMonos, prDCs and, strikingly, huge increases in prB cell proportions well before then. These data raise the strong possibility that a considerable portion of prions that we injected IP passively traveled through lymphatics draining the PC, arriving in MedLNs via afferent lymphatics and captured by resident immune cells, as has been observed for other free antigens ${ }^{10,26,28}$. We substantiated this possibility for prions by identifying significant numbers of prionophilic resident DCs, SCS MФs, innate B1 and follicular B2 cells in MedLNs 2 to 6 HPI. Adoptive transfer experiments revealed a small number of monocytes and B2 cells, but not migratory DCs, MФs and B1 cells, pre-loaded with prions from donor mice, present in MedLNs of recipient mice at these times. We assert that the very small number of monocytes are not likely to transport the large amount of prions to MedLNs and transfer them to very large numbers of SC M $\Phi$ s there. These data compellingly support a mechanism of cell autonomous movement of smaller prion aggregates from the infection site to draining lymph nodes.

Data supporting a cell autonomous route of lymphotropic prion trafficking also lends insight into intranodal prion movement. The incredible proportion of prB cells in MedLNs at early time points indicates that $\mathrm{B}$ cells are most likely receiving prions from other immune cells, probably SCS MФs and resident DCs within the lymph nodes, consistent with current models of intranodal antigen trafficking $^{26,29}$. B cells are likely not the only cells receiving prions from other cells in the LN. FDCs, which trap and replicate prions in germinal centers, originate from stromal cells and are sessile, permanent residents in $\mathrm{LNs}^{30,31}$. Thus, they must receive prions intranodally from another source, perhaps prB cells or by directly capturing small prion aggregates arriving in the LN through follicular conduits. We also reproducibly observed a considerable proportion of $\operatorname{pr} \mathrm{T}$ cells in MedLNs but not in the PC, at all time points, further supporting intranodal, intercellular prion transfer. Future experiments documenting intranodal prion trafficking in real time using multiphoton intravital microscopy will confirm this hypothesis.

Numerous studies corroborate the facilitative role of Complement in peripheral prion pathogenesis. In this study we found that fewer DCs captured prions without $\mathrm{C} 1 \mathrm{q}$ or $\mathrm{C} 3$ and fewer monocytes captured prions without C3, while neutrophil capture dramatically increased in the PC. MФs predominantly and efficiently captured prions seemingly independent of $\mathrm{C} 1 \mathrm{q}$ and $\mathrm{C} 3$. We interpret these data to reveal that DCs and monocytes require $\mathrm{C} 1 \mathrm{q}$ and/or C3 for optimal prion retention, perhaps through Complement receptors like Mac-1, SIGN-R1 or Calreticulin ${ }^{7,28}$. The neurotoxic prion peptide $\operatorname{PrP}_{106-126}$ has been shown to bind the $\mathrm{G}$ protein-coupled receptor, formyl peptide receptor-like 1 (FPRL-1) on, and enhance proinflammatory cytokine production from monocytes ${ }^{32}$. Prions binding FPRL-1 on monocytes could explain this prionophil's apparently reduced dependence on Complement for prion capture.

Based on the data described here, we propose an updated, more detailed model of lymphotropic and intranodal prion trafficking by immune cells (Figure 8). Biphasic lymphotropic transport of prions occurs from the initial entry site upon peripheral prion infection. A first wave of smaller prion aggregates passively percolate through interstitia, and collect into and quickly travel through the lymphatic system to draining lymph nodes. A small number of monocytes also rapidly and actively transport larger prion aggregates. SCS MФs capture free prions as they emerge from afferent lymphatic vessels, while resident DCs extend processes into follicular conduits and extract free prions. MФs at the site of infection capture large and small aggregates with or without Complement, perhaps by scavenger or other phagocytic receptors, or even macropinocytosis. These 


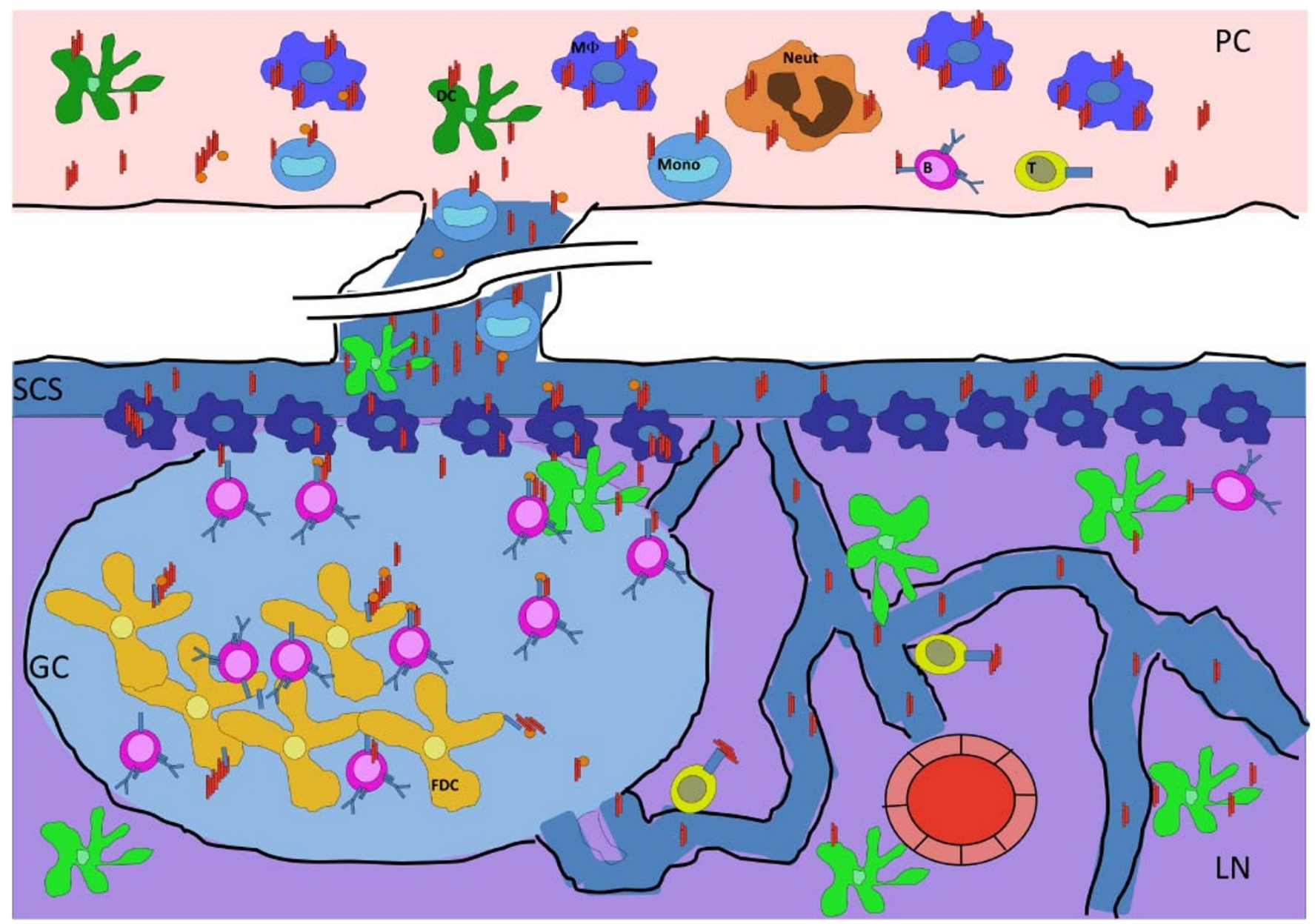

Figure 8 Prion Trafficking Model. Immune cells encounter prions in the PC and MedLN. M $\phi$, DCs, monocytes, neutrophils, B and T cells have all been shown to associate with prions in the PC and MedLN early after infection. Small prion particles traffic passively through the lymphatic system and enter the lymph node through afferent lymphatic vessels where they encounter B cells through follicular conduits. DCs may also access prions through protrusion of their dendrites through tight junctions into follicular conduits. SCS M $\phi$ s trap larger prion or prion-complement immune complexes through scavenger or complement receptor 3 and may present them to underlying follicular B cells. Inflammatory monocytes actively transport prions to SCS M $\phi$ s, B cells, or DCs in the draining lymph node. B cells facilitate intrafollicular prion trafficking to FDCs for efficient prion replication.

peripheral MФs more likely degrade and/or sequester the majority of prions, whereas DCs and monocytes preferentially retain Complement-opsonized prions on their cell surfaces via Complement receptors. These prDCs and prMonos deliver the second wave of prions to draining LNs at least 12 hours later.

Inside LNs, SCS MФs capture free prions or receive them from incoming prDCs and prMonos. prDCs or SCS prMФs (which are more prone to present antigen than phagocytic peripheral prMФs) transfer prions to follicular B2 cells (and perhaps a few T cells), most likely but not necessarily aided by Complement. prB2 cells then shuttle prions from the SCS or follicular conduits to FDCs, which express copious amounts of $\operatorname{PrP}^{\mathrm{C}}$ that is converted into $\mathrm{PrP}^{\mathrm{Sc}}$ in this optimized prion bioreactor. Cell autonomous prions not captured by SCS MФs or resident DCs may encounter follicular B2 cells at follicular conduit termini or travel deep into the follicle where FDCs directly bind them. While prion replication certainly requires $\operatorname{PrP}^{\mathrm{C}}$, incunabular prion capture and trafficking does not.

\section{Methods}

Mice. $\mathrm{PrP}^{-1-}(\mathrm{C} 57 \mathrm{BL} / 6 \mathrm{X} 129 \mathrm{sv}), \mathrm{Tg}(\mathrm{cerPrP}) 5037$ and $\mathrm{Cl}^{-1-}$ mice were generated as previously described ${ }^{33-35}$. FVB, and $\mathrm{C}^{-1-}(\mathrm{C} 3 \mathrm{tm} 1 \mathrm{Crr} / \mathrm{J})$ mice were purchased from The Jackson Laboratory (Bar Harbor, ME). All mice were bred and maintained at Lab Animal Resources, accredited by the Association for Assessment and Accreditation of Lab Animal Care International, in accordance with protocols approved by the Institutional Animal Care and Use Committee at Colorado State University.
Fluorescent Prions. Enrichment and fluorochrome labeling of prions were performed as previously described ${ }^{36-38}$ with slight modifications. $10 \%$ Elk brain homogenate prepared in $0.32 \mathrm{M}$ sucrose, $150 \mathrm{uM} \mathrm{NaCl}, 4$ uM EDTA diluted in PBS (PMCA buffer) were centrifuged at $3,000 \mathrm{~g}$ for 10 minutes at $4^{\circ}$. The resulting supernatant were removed and saved and the pellet treated in PMCA buffer then centrifuged again at $3,000 \mathrm{~g}$ for 10 minutes at $4^{\circ} \mathrm{C}$. Supernatants were then pooled and centrifuged at $100,000 \mathrm{~g}$ for $1 \mathrm{hr}$ at $4^{\circ} \mathrm{C}$ and the resulting pellet treated with triton $\mathrm{X}-100$ at $0^{\circ} \mathrm{C}$ at a final detergent concentration of $2 \% \mathrm{wt} / \mathrm{vol}$, bringing the protein concentration to $5 \mathrm{mg} / \mathrm{ml}$ in TBS measured by the Bradford assay. The sample was then chilled on ice for 30 minutes and centrifuged at $100,000 \mathrm{~g}$ for 30 minutes at $0^{\circ} \mathrm{C}$ The pellet was then washed twice at $0^{\circ} \mathrm{C}$ in $10 \mathrm{mM}$ Tris HCL, $0.1 \mathrm{NaCl}, 1 \mathrm{mM}$ EDTA, $5 \mathrm{mM}$ PMSF at a $\mathrm{pH}$ of 7.4 with and without $2 \%$ Triton X-100. The supernatant was discarded and the pellet resuspended in PBS containing 1\% (wt/vol) sarcosyl and protease inhibitors and stirred for 2 hours at $37^{\circ} \mathrm{C}$ before centrifuging through $0.32 \mathrm{M}$ sucrose in PBS at $100,000 \mathrm{~g}$ for 60 minutes at $10^{\circ} \mathrm{C}$. The pellet was resuspended in a $2.3 \mathrm{M} \mathrm{NACl}, 5 \%$ sarcosyl solution and sonicated 5 times at 40 second bursts. The fractions were centrifuged at $13,000 \mathrm{~g}$ for 15 minutes at $4{ }^{\circ} \mathrm{C}$, washed twice with TBS and stored at $-70^{\circ} \mathrm{C}$ or conjugated to Dylight 649 using the Dylight Antibody Labeling Kit according to manufacturere's protocol (Thermo Scientific Pierce).

PK digestion and western blotting. Samples were digested with $50 \mu \mathrm{g} / \mathrm{ml} \mathrm{PK}$ (Roche) for $30 \mathrm{~min}$ at $37^{\circ} \mathrm{C}$. The reaction was stopped by adding lithium dodecyl sulfate sample loading buffer (Invitrogen) and incubating at $95^{\circ} \mathrm{C}$ for $5 \mathrm{~min}$. Proteins were electrophoretically separated through $12 \%$ sodium dodecyl sulfate-polyacrylamide gels (Invitrogen), and transferred to polyvinylidene difluoride membranes (Millipore). Non-specific membrane binding was blocked by incubation in 5\% milk blocking solution (Bio-Rad) for $1 \mathrm{~h}$. Membranes were then incubated for $1 \mathrm{~h}$ at room temperature with horseradish peroxidase-conjugated Bar224 anti-PrP monoclonal antibody (SPI bio) diluted 1:20,000 in Superblock (Pierce), washed 6 X10 min in 
PBS with $0.2 \%$ Tween 20, and incubated for 5 min with enhanced chemiluminescent substrate (Millipore). Membranes were digitally photographed using the FujiDoc gel documentation system equipped with a cooled charge-coupled diode camera (Fuji).

Prion Inoculations. Prion Inoculations were performed as previously described ${ }^{37,38}$. Briefly, ice were inoculated IP with $100 \mu \mathrm{l}$ of PBS, or various concentrations of red fluorescent microspheres (Flourophex) or a suspension of prion aggregates described above.

Live animal imaging. Mice were inoculated SC and PO with indicated amounts of fluorescent beads or prions, and visualized while anesthetized with $3 \mathrm{~L} / \mathrm{min}$ Isofluorane in an IVIS 100 live animal imager (Caliper Life Sciences,Hopkinton, MA) at the indicated time points. We analyzed images using Living Image 4.0 software (Caliper).

Intraperitoneal wash. Immediately after euthanization of mice by $\mathrm{C}_{2}$ asphyxiation $10 \mathrm{ml}$ of PBS was injected into the peritoneal cavity of each mouse using a $12 \mathrm{ml}$ syringe and 25 gauge $x 1 / 2$ in polypropylene hub hypodermic needle. The mice were set on a rocker or gently rocked manually for 2 minutes. As much PBS as possible was recovered using the same $12 \mathrm{ml}$ syringe and a 16 gauge X $1 \frac{1 / 2}{2}$ in polypropylene hub hypodermic needle.

The peritoneal wash fluid was collected in a $15 \mathrm{ml}$ conical tube (Falcon) and centrifuged at $250 \mathrm{xg}$ for five minutes. The supernatant was discarded and the pellet re-suspended in $1 \mathrm{ml}$ fluorescence activated cell sorting (FACS) buffer and transferred to a $1.5 \mathrm{ml}$ eppendorf tube for staining.

Isolation of cells from tissues. Following intraperitoneal wash the mediastinal lymph nodes (and where appropriate inguinal, spleen and mesenteric lymph nodes) were removed from the mice. Lymph nodes were stored in $1 \mathrm{ml}$ RMPI medium on ice for no longer than $30 \mathrm{~min}$ prior to separation of cells. The lymph nodes were transferred to a $40 \mu \mathrm{m}$ nylon cell strainer (Falcon ref 352340) with 1-3 ml PBS. Lymph nodes were pressed through the screen with the plunger of a sterile $1 \mathrm{ml}$ syringe. Loose cells were rinsed through the screen with an additional 1-2 ml PBS and the filtrate was transferred to a $15 \mathrm{ml}$ conical tube. The plate was washed with 4-6 $\mathrm{ml}$ of PBS and transferred to the same $15 \mathrm{ml}$ conical. The $15 \mathrm{ml}$ conical containing the single cell suspension from the lymph node was spun at $1000 \mathrm{rpm}$ for $5 \mathrm{~min}$. The supernatant was discarded and the pellet re-suspended in $1 \mathrm{ml}$ FACS buffer and transferred to a $1.5 \mathrm{ml}$ eppendorf tube for staining.

Antibody staining of cells. $10^{6}$ cells were aliquoted from single cell suspensions and pelleted at $250 \mathrm{xg}$ for 5 minutes on a bench top centrifuge. Samples were washed twice in FACS buffer ( $0.1 \%$ BSA, $10 \mathrm{mM}$ EDTA in 1XPBS) by resuspending the cell pellet in $1 \mathrm{ml} \mathrm{FACS}$ followed by centrifugation at $1000 \mathrm{rpm}$ for 5 minutes. Fc receptors were blocked using $2 \mathrm{ng} / \mathrm{ml}$ solution of Purified rat anti-mouse CD16/CD32

(BD Pharmingen) and incubated on ice for $20 \mathrm{~min}$. Fc block was removed by washing once with FACS buffer before staining solution was added to cell pellets. Cell pellets were stained using $50 \mathrm{ul}$ of a $1 \mathrm{ng} / \mathrm{mL}$ solution of the antibodies listed in Table S1. Cells were washed twice following staining to remove unbound antibody and red blood cells were lysed by adding $1 \mathrm{ml}$ of ACK buffer $(150 \mathrm{mM} \mathrm{NH} 4 \mathrm{Cl}, 10 \mathrm{mM}$ $\mathrm{KHCO}_{3}, 0.1 \mathrm{mM}$ EDTA) to the cell pellet and immediately centrifuging at $250 \mathrm{xg}$ for 5 minutes. The supernatant was removed and cell pellets were resuspended in $1 X$ FACS for analysis.

Confocal Microscopy. Antibody-stained peritoneal cells were cytospun onto glass slides and mounted with ProLong Gold medium (Life Technologies, Grand Island, $\mathrm{NY}$ ) and dried overnight at $4^{\circ} \mathrm{C}$. We acquired images with a LSM 510 Meta confocal microscope and software (Zeiss).

Flow cytometric and statistical analyses. Flow cytometry data was acquired using a DakoCytomation CyAnADP flow cytometer and analyzed using FlowJo version 8 (Tree Star, Ashland, OR). Nonparametric statistical analyses were performed using GraphPad Prism 5 (La Jolla, CA).

1. Prusiner, S. B. Novel proteinaceous infectious particles cause scrapie. Science 216, 136-144 (1982).

2. Büeler, H. R. et al. Mice devoid of PrP are resistant to scrapie. Cell 73, 1339-1347 (1993).

3. Brown, K. L. et al. Scrapie replication in lymphoid tissues depends on prion protein- expressing follicular dendritic cells. Nat Med 5, 1308-1312 (1999).

4. Montrasio, F. et al. Impaired prion replication in spleens of mice lacking functional follicular dendritic cells. Science 288, 1257-1259 (2000).

5. Götze, O. \& Müller-Eberhard, H. J. The c3-activator system: an alternate pathway of complement activation. J. Exp. Med. 134, 90-108 (1971).

6. Jiang, H., Burdick, D., Glabe, C. G., Cotman, C. W. \& Tenner, A. J. beta-Amyloid activates complement by binding to a specific region of the collagen-like domain of the C1q A chain. J. Immunol. 152, 5050-5059 (1994).

7. Sim, R. B., Kishore, U., Villiers, C. L., Marche, P. N. \& Mitchell, D. A. Clq binding and complement activation by prions and amyloids. Immunobiology 212, 355362 (2007).

8. Aucouturier, P. Infected splenic dendritic cells are sufficient for prion transmission to the CNS in mouse scrapie. Journal of Clinical Investigation 108, 703-708 (2001).
9. Beringue, V. et al. Role of spleen macrophages in the clearance of scrapie agent early in pathogenesis. J. Pathol. 190, 495-502 (2000).

10. Manolova, V. et al. Nanoparticles target distinct dendritic cell populations according to their size. Eur. J. Immunol. 38, 1404-1413 (2008).

11. Beier, R. \& Gebert, A. Kinetics of particle uptake in the domes of Peyer's patches. American Journal of Physiology-Gastrointestinal and Liver Physiology 275, G130G137 (1998).

12. Itano, A. A. et al. Distinct dendritic cell populations sequentially present antigen to $\mathrm{CD} 4 \mathrm{~T}$ cells and stimulate different aspects of cell-mediated immunity. Immunity 19, 47-57 (2003).

13. Flores-Langarica, A., Sebti, Y., Mitchell, D. A., Sim, R. B. \& MacPherson, G. G. Scrapie pathogenesis: the role of complement C1q in scrapie agent uptake by conventional dendritic cells. J. Immunol. 182, 1305 (2009).

14. McCulloch, L. et al. Follicular Dendritic Cell-Specific Prion Protein ( $\mathrm{PrPc})$ Expression Alone Is Sufficient to Sustain Prion Infection in the Spleen. PLoS Pathogens 7, e1002402 (2011).

15. Zabel, M. D. et al. Stromal complement receptor CD21/35 facilitates lymphoid prion colonization and pathogenesis. J. Immunol. 179, 6144-6152 (2007).

16. Carp, R. I. \& Callahan, S. M. In vitro interaction of scrapie agent and mouse peritoneal macrophages. Intervirology 16, 8-13 (1981).

17. Sassa, Y., Inoshima, Y. \& Ishiguro, N. Bovine macrophage degradation of scrapie and BSE PrPSc. Veterinary Immunology and Immunopathology 133, 33-39 (2010).

18. Sigurdson, C. J. et al. $\operatorname{PrP}(\mathrm{CWD})$ lymphoid cell targets in early and advanced chronic wasting disease of mule deer. J. Gen. Virol. 83, 2617-2628 (2002).

19. Zhou, H. et al. Induction of macrophage migration by neurotoxic prion protein fragment. J. Neurosci. Methods 181, 1-5 (2009).

20. Cordier-Dirikoc, S. \& Chabry, J. Temporary Depletion of CD11c+ Dendritic Cells Delays Lymphoinvasion after Intraperitonal Scrapie Infection. J. Virol. 82, 89338936 (2008).

21. Defaweux, V. et al. Interfaces between dendritic cells, other immune cells, and nerve fibres in mouse Peyer's patches: potential sites for neuroinvasion in prion diseases. Microsc. Res. Tech. 66, 1-9 (2005).

22. Huang, F. P., Farquhar, C. F., Mabbott, N. A., Bruce, M. E. \& MacPherson, G. G. Migrating intestinal dendritic cells transport $\operatorname{Pr} \mathrm{P}(\mathrm{Sc})$ from the gut. J. Gen. Virol. 83, 267-271 (2002).

23. Raymond, C. R., Aucouturier, P. \& Mabbott, N. A. In vivo depletion of CD11c+ cells impairs scrapie agent neuroinvasion from the intestine. J. Immunol. 179, 7758-7766 (2007).

24. Mabbott, N. A. The complement system in prion diseases. Current Opinion in Immunology 16, 587-593 (2004).

25. Mempel, T. R., Henrickson, S. E. \& Andrian, Von, U. H. T-cell priming by dendriticcells in lymph nodes occurs in three distinct phases. Nature 427, 154 159 (2004).

26. Junt, T. et al. Subcapsular sinus macrophages in lymph nodes clear lymph-borne viruses and present them to antiviral B cells. Nature 450, 110-114 (2007).

27. Gonzalez, S. F. et al. Trafficking of B Cell Antigen in Lymph Nodes. Annu. Rev. Immunol. 29, 215-233 (2011).

28. Gonzalez, S. F. et al. Capture of influenza by medullary dendritic cells via SIGN-R1 is essential for humoral immunity in draining lymph nodes. Nature Publishing Group 11, 427-434 (2010).

29. Carrasco, Y. R. \& Batista, F. D. B cells acquire particulate antigen in a macrophagerich area at the boundary between the follicle and the subcapsular sinus of the lymph node. Immunity 27, 160-171 (2007).

30. Li, L. \& Choi, Y. S. Follicular dendritic cell-signaling molecules required for proliferation and differentiation of GC-B cells. Semin Immunol 14, 259-266 (2002).

31. MacLennan, I. C. Germinal centers. Annu. Rev. Immunol. 12, 117-139 (1994).

32. Le, Y. et al. Cutting Edge: The Neurotoxic Prion Peptide Fragment PrP(106-126) Is a Chemotactic Agonist for the G Protein-Coupled Receptor Formyl Peptide Receptor-Like 1. J. Immunol. 166, 1448-1451. (2001).

33. Büeler, H. et al. Normal development and behaviour of mice lacking the neuronal cell-surface PrP protein. Nature 356, 577-582 (1992).

34. Browning, S. R. et al. Transmission of prions from mule deer and elk with chronic wasting disease to transgenic mice expressing cervid PrP. J. Virol. 78, 1334513350 (2004)

35. Botto, M. et al. Homozygous $\mathrm{Clq}$ deficiency causes glomerulonephritis associated with multiple apoptotic bodies. Nat Genet 19, 56-59 (1998).

36. Safar, J. et al. Molecular mass, biochemical composition, and physicochemical behavior of the infectious form of the scrapie precursor protein monomer. Proc. Natl. Acad. Sci. U.S.A. 87, 6373-6377 (1990).

37. Johnson, T. E. et al. Monitoring Immune Cells Trafficking Fluorescent Prion Rods Hours after Intraperitoneal Infection. J Vis Exp doi:10.3791/2349 (2010).

38. Nichols, T. A. et al. Detection of protease-resistant cervid prion protein in water from a CWD-endemic area. Prion 3, 171-183 (2009).

\section{Ackonwledgments}

The project described was supported by Grant Number R01NS56379 from the National Institute Of Neurological Disorders And Stroke. The content is solely the responsibility of the authors and does not necessarily represent the official views of the National Institute Of 
Neurological Disorders And Stroke or the National Institutes of Health. We thank Kevin O'Halloran, Mercedes González-Juarrero and Laura Chubb for help with confocal microscopy, flow cytometry and live imaging.

\section{Author contributions}

$\mathrm{BM}, \mathrm{TJ}, \mathrm{AF}$ and $\mathrm{MZ}$ performed the experiments. CM-R and CW enriched and labeled prions. $\mathrm{BP}$ and $\mathrm{HB}$ bred, maintained and organized mice and aided mouse experiments $\mathrm{BM}, \mathrm{AA}, \mathrm{SD}$ and $\mathrm{MZ}$ designed the experiments and wrote the paper.

\section{Additional information}

Supplementary information accompanies this paper at http://www.nature.com/ scientificreports

Competing financial interests: The authors declare no competing financial interests. License: This work is licensed under a Creative Commons

Attribution-NonCommercial-NoDerivative Works 3.0 Unported License. To view a copy of this license, visit http://creativecommons.org/licenses/by-nc-nd/3.0/

How to cite this article: Michel, B. et al. Incunabular Immunological Events in Prion Trafficking. Sci. Rep. 2, 440; DOI:10.1038/srep00440 (2012). 